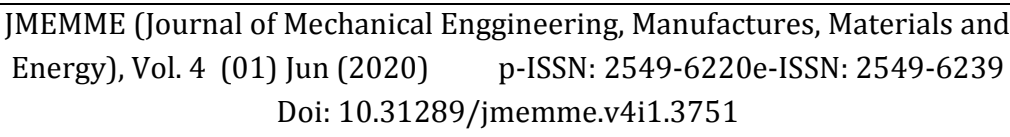

JMEMME (Journal of Mechanical Engineering, Manufactures, Materials and Energy)

\title{
Pemodelan dan Simulasi Sistem Roda Gigi Menggunakan Pendekatan Multi Body Dynamic Dengan Metode Menghitung Parameter Roda Gigi Pada Roda Senyawa
}

\section{Modeling and Simulation of a Gear System Using a Multi-Body Dynamic Approach with the Method of Calculating Gear Parameters on a Compound Wheel}

\author{
Junaidi1)*, Amrinsyah ${ }^{2)}$ \\ 1) Program Studi Teknik Mesin Universitas Harapan Medan \\ 2) Program Studi Teknik Mesin, Universitas Medan Area \\ Diterima: 07-05-2020 ; Disetujui: ; Diterbitkan: 30-06-2020 \\ *Corresponding author: junaidi.unhar@harapan.ac.id
}

\begin{abstract}
Abstrak
Dalam laporan ini menyajikan skema desain dan prinsip operasi transmisi gigi dengan komposit roda dan elemen elastis. Teknik dan hasil analisis ini ditujukan untuk menentukan tingkat mobilitas roda gigi dengan roda komposit dan elemen elastis. Dinamika pendaratan pesawat pada kapal induk terdiri dari proses perambatan gelombang sementara di tali dan perlambatan kecepatan pesawat yang halus. Hal Ini memberikan tantangan besar dalam simulasi seluruh proses karena membutuhkan waktu yang cepat untuk menjamin kestabilan dan membutuhkan langkah waktu yang besar dalam mengurangi waktu perhitungan. Model dinamika multibodi skala penuh dari sistem roda gigi penangkapan dipergunakan untuk mengatasi masalah ini. Metode ini memanfaatkan skema integrasi langkah-langkah variabel dalam perhitungan waktu pendaratan tersebut. Metode ini menggunakan elemen kabel baru yang mampu menggambarkan perpindahan besar. Ruang tiga dimensi diadopsi untuk menyatukan kabel kawat, sehingga gaya peredaman dapat digunakan untuk memodelkan efek sistem hidrolik. Simulasi dinamis menunjukkan bahwa tegangan kabel didominasi oleh propagasi, tolakan, dan superposisi dari gelombang tegangan selama tahap awal proses penangkapan dan selanjutnya goncangan akan cepat hilang oleh sheave damper instalasi dan peredam jangkar kabel.
\end{abstract}

Kata Kunci: Pemodelan, Simulasi, Roda Gigi, Multy Body Dinamic, Roda senyawa

\begin{abstract}
In this report presents the design scheme and operating principle of gear transmission with composite wheels and elastic elements. The techniques and results of this analysis are intended to determine the level of gear mobility with composite wheels and elastic elements. The dynamics of aircraft landing on an aircraft carrier consist of a process of transient wave propagation on a rope and a smooth deceleration of an aircraft's speed. This presents a big challenge in the simulation of the whole process because it requires fast time to ensure stability and requires a large time step in reducing calculation time. A full-scale multi-body dynamics model of the capture gear system is used to overcome this problem. This method utilizes the integration scheme of variable steps in the calculation of the landing time. This method uses a new cable element that is able to describe large displacement. Three-dimensional space is adopted to unify the wire cable, so that the damping force can be used to model the effects of the hydraulic system. Dynamic simulations show that cable stresses are dominated by propagation, repulsion, and superposition of voltage
\end{abstract}


Junaidi, Pemodelan dan Simulasi Sistem Roda Gigi ...

waves during the initial stages of the capture process and subsequently shocks will be quickly dissipated by the installation sheave damper and cable anchor dampers.

Keywords: Modeling, Simulation, Gears, Multibody Dynamic, Compound Wheel

How to Cite: Junaidi, 2020, Pemodelan dan Simulasi Sistem Roda Gigi Menggunakan Pendekatan Multi Body Dynamic Dengan Metode Menghitung Parameter Roda Gigi Pada Roda Senyawa, JMEMME (Journal of Mechanical Enggineering, Manufactures, Materials and Energy), 4(01): 40-49 


\section{PENDAHULUAN}

Desain transmisi roda gigi ini berisi tentang roda gigi penggerak dan berpenggerak, roda gigi mentransmisikan gerakan rotasi dari poros roda gigi ke roda gigi penggerak kemudian ke roda gigi yang digerakkan. Kelemahan dari transmisi ini adalah kurangnya penyerapan fluktuasi puncak pada beban (momen) pada poros transmisi saat menggunakan transmisi penggerak mesin teknologi yang beroperasi dengan beban variabel. Hal ini menyebabkan keausan yang cepat pada gigi roda, kebisingan tinggi, kegagalan bantalan bantalan, sehingga mengurangi sumber daya pengoperasian transmisi gigi, terutama pada mode operasi kecepatan tinggi.

Sistem roda gigi penangkapan adalah unit penting yang dilengkapi oleh kapal induk untuk membantu pendaratan pesawat berkecepatan tinggi di dalam jarak terbatas. Prototipe pertamanya ditemukan pada tahun 1911 oleh Hugh Robinson [1], tali yang melintasi geladak itudigenggam dan ditarik oleh tailhook pesawat, mengangkat karung pasir ada kaitan dengan tali melalui katrol dan perlambatan pesawat terbang. Setelah itu, hidrolik menahan roda gigi, yang menggantikan gaya perlambatan dari gravitasi karung pasir keredaman hidrolik, muncul [2]. Segera menjadi populer di pembawa pesawat modern karena kekuatan hidrolik dapat disesuaikan mendaratkan pesawat dengan bobot dan kecepatan berbeda dengan mekanisme yang sama. Yang paling sering dilengkapi adalah MK7 ketika roda gigi penahan hidraulik.
Proses penangkapan yang khas mengandung dua tahap berurutan dengan karakter dinamis yang sangat berbeda: tahap pertama didominasi oleh perambatan dan refleksi gelombang tegangan dalam tali, dipicu oleh dampak antara liontin dan tailhook; tahap kedua diatur oleh quasi- stable gaya hidrolik ketika tekanan gelombang dikatakan dan diikuti oleh gerakan kabel besar secara halus dan deselerasi cepat pesawat. Seluruh proses sangat rumit bahwa beberapa masalah mekanis sulit dijawab analisis teori dan bahkan simulasi numerik, seperti kapan mereka stres maksimum di tali akan terjadi dan di mana itu, apa adalah faktor kunci ketika pesawat mendarat atau menyimpang dari tengah, bagaimana cara mengontrol gaya hidrolik pastikan bahwa pesawat ditangkap dalam jarak terbatas menyertai proses perlambatan yang stabil. Meskipun banyak sarjana telah mengabdikan diri untuk mempelajari berbagai aspek. Sistem tangkap, masih banyak masalah liontin geladak mengakibatkan beberapa kecelakaan penerbangan saat ini, yang terbaru adalah frakturtali di USS George Washington pada tahun 2003 [3]. Dalam literatur, Billec [4] menguji secara eksperimental akselerasi pesawat dengan panjang liontin geladak yang berbeda pada tahun 1967. Dia menunjukkan bahwa deselerasi maksimum berkurang 14 persen ketika liontin meningkat dari 100 kaki menjadi 130 kaki. Pada 2010, Zhuokun et al. [5] [6] dihitung secara analitis ketegangan mantap maksimum dari tali kawat dengan quasi steady asumsi pendaratan; mereka menyimpulkan bahwa maksimal. 
Tujuan penelitian ini ialah pemodelan dinamika multibodi skala penuh dari sistem roda gigi penangkapan dengan memanfaatkan skema integrasi langkah-langkah variabel berdasarkan dinamika pendaratan pesawat pada kapal induk yang melibatkan proses perambatan gelombang sementara di tali dan halus perlambatan pesawat.

\section{METODE}

Nilai puncak fluktuasi beban pada poros transmisi dapat dikurangi dengan cara meningkatkan masa pakai, dan juga mengurangi kebisingan, terutama pada mode operasi kecepatan tinggi, desain roda gigi, termasuk elemen elastis yang telah ditingkatkan. Roda gigi (Gambar. 1) penggerak komposit 1 , penggerak roda gigi 2 , yang mencakup pelak dengan gigi 3 dan 4, penghubung 5 dan 6 dipasang dengan kaku pada poros 7 dan 8. Di antara pelak 3, 4, 5, dan 6 terdapat busing karet elastis yang dipasang dengan kaku pada poros 9, 10, 11, dan 12. [3]. Dalam hal ini, roda gigi 2 dan gigi 1 memiliki dua bagian karet yaitu karet bagian dalam 9, 10 dan luar 11 dan 12. Kekakuan melingkar C1 dari busing karet 9 dan 12 sama yang terbuat dari jenis karet yang sama, seperti kekakuan torsional C2 dari busing karet (grade karet) 10 dan 11 dipilih sama, maka C2> C1.

Penggerak roda gigi beroperasi sebagai berikut: Lingkar 3 dengan roda gigi penggerak 1 menerima gerakan rotasi dari motor penggerak (tidak diperlihatkan dalam gambar), poros 7 , hub 5, melalui busing elastis 9 dan 11 . Ketika roda gigi 1 dan 2 roda gigi bergerak, gerakan rotasi ditransmisikan ke pelak 4 dengan gigi dan melalui busing elastis 12 dan 10 dari hub 6 dan ke poros 8. Di bawah pengaruh beban eksternal dan resistensi teknologi, torsi pada poros 8 berubah. Selain itu, nilai puncak fluktuasi momen diserap oleh busing elastis 10 dan 12. Selanjutnya, beban puncak tambahan diserap dalam busing tangguh 9 dan 11, roda gigi penggerak 1 (roda gigi). Dalam hal ini, torsi pada poros 7 dan 8 akan dihaluskan sampai batas tertentu.

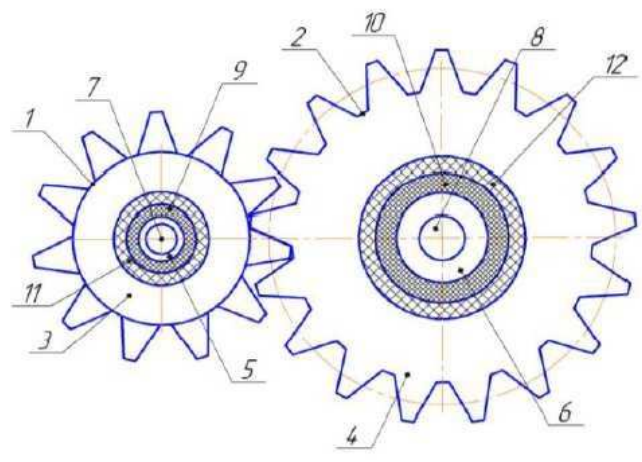

Gambar 1. Wheelwork

Ketika mentransmisikan momen antara roda gigi 1 dan wheelwork busing karet pada nomor 9 dan 12 akan berubah bentuk dalam arah melingkar, karena kekakuan melingkarnya lebih besar dari pada kekakuan melingkar dari busing karet 10 dan 11. Dalam hal ini, busing karet 10 dan 11 akan lebih berubah bentuk karena $\mathrm{C} 2>\mathrm{C} 1$. Ini memberikan berbagai frekuensi penyerapan fluktuasi momen yang ditransmisikan antara gigi 1 dan gigi 2. Transmisi roda gigi memberikan pengurangan nilai puncak fluktuasi beban pada poros transmisi, peningkatan kehidupan pelayanan, dan juga mengurangi kebisingan, terutama di tempat tinggi mode kecepatan dan berbagai muatan teknologi. 
Analisis Struktur Mekanisme Gigi Dengan Roda Majemuk

Analisis mekanisme dibagi menjadi: struktural, kinematik dan dinamis [7]. Bersamaan dengan itu, struktur alanalisis mekanisme itu penting, di mana derajat mekanisme bergerak ditentukan. Tingkat mobilitas mekanisme akan memungkinkan penentuan jumlah tautan bergerak, pasangan kinematik, serta jumlah drive. Diketahui bahwa tingkat mekanisme mobile planar adalah ditentukan oleh rumus Chebyshev [8]. Harus mencatat bahwa ketika menggunakan rumus Chebyshev, tautan dari mekanisme dianggap sangat kaku, elastis dan obligasi tidak diperhitungkan.

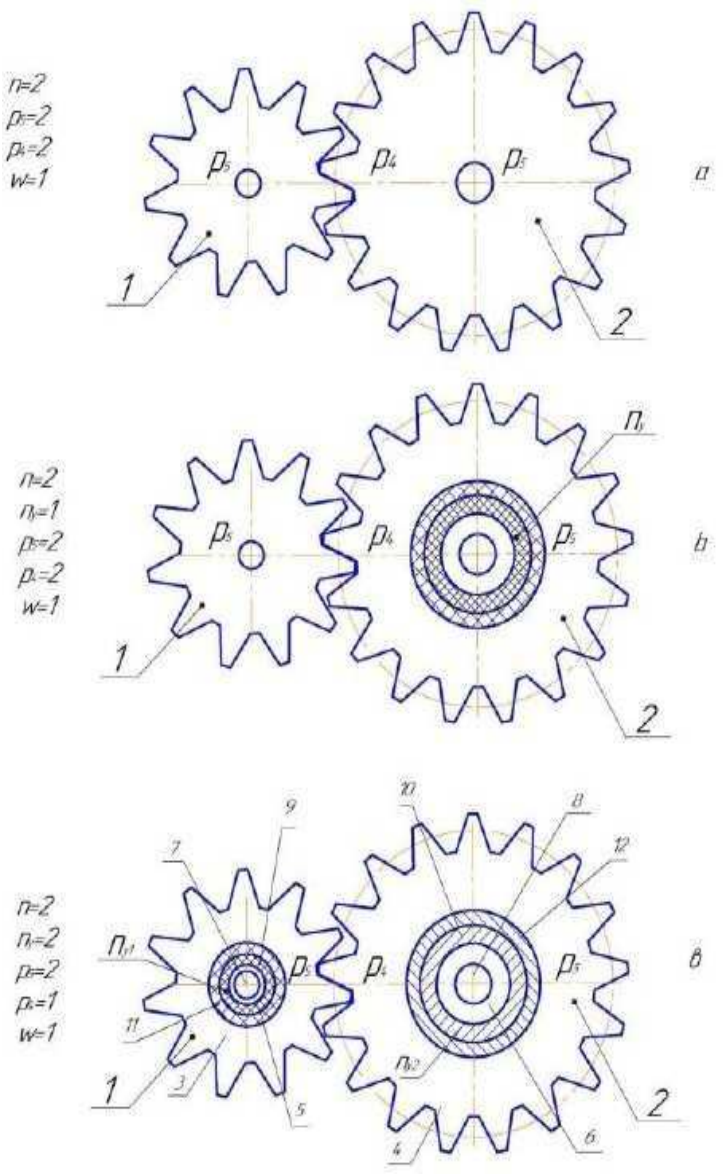

Gambar 2. Sketsa roda gigi
Gambar 2 menunjukkan tiga opsi untuk roda gigi: a. roda gigi yang terdiri dari gigi 1 dan roda 2; roda b-driven dibuat integral, memiliki elemen elastis; di kedua gigi dibuat integral. Pertimbangkan analisis struktural dari mekanisme roda gigi ditunjukkan pada Gambar. 1. Tingkat mobilitas yang dipertimbangkan mekanisme ditentukan sesuai dengan teknik yang diberikan dalam persamaan 1 [9].

$\mathrm{W}=3 n-2 P_{5}-P_{4}$

Dimana, $\mathrm{n}$ adalah jumlah tautan bergerak, P5 adalah jumlah pasangan kinematik dari kelas kelima, P4 adalah jumlah pasangan kinematik dari kelas empat. Untuk semua varian mekanisme gigi yang ditunjukkan pada Gambar. 1, tingkat mobilitas sama dengan kesatuan. Pada saat bersamaan untuk menentukan kelebihan ikatan dalam mekanisme itu dapat menyebabkan penurunan yang signifikan dalam sumber daya pekerjaan karenauntuk meningkatkan gesekan, getaran, reaksi yang tidak perlu, dll. Ikatan berlebih ditentukan dengan menggunakan persamaan 2 .

$$
q=W-6 n+5 P_{5}+4 P_{4}
$$

Untuk mengurangi gesekan pada pasangan kinematik, tambah sumber daya mekanismenya, maka direkomendasikan penggunaan elemen elastis dimekanisme. Untuk ini, disarankan untuk memperhitungkan elemen elastis saat menentukan kelebihan ikatan dalam mekanisme mempergunakan persamaan 3 [7]. 
Junaidi, Pemodelan dan Simulasi Sistem Roda Gigi ...

$q=W-6 n+5 P_{5}+4 P_{4} \cdot n_{3}$

Dimana, n y - adalah jumlah elemen elastic dalam mekanisme.

Dari persamaan 3 terlihat bahwa masing- masing unsur elastis termasuk dalam mekanisme mengurangi kelebihan ikatan oleh satu. Selain itu: Untuk opsi "a" dalam gambar. 1: $q=3$; Untuk opsi "b" dalam gambar. 1: $q=2$; Untuk opsi "c" dalam gambar. $1: \mathrm{q}=1$.

Analisis hasil menunjukkan bahwa opsi ketiga (Gambar 2 c) dianggap yang paling dapat diterima, di mana kelebihan ikatan direduksi menjadi satu. Untuk menghilangkan kelebihan secara lengkap koneksi dalam transmisi gir, direkomendasikan itu bantalan dipasang pada poros gigi digerakkan di perumahan dengan bantal karet.

Jelas bahwa, roda gigi banyak digunakan dimesin teknologi. Kerugian utama dari ini mekanisme adalah interaksi kaku dari gigi roda ketika mereka terlibat, dan transmisi perubahan langsung dalam beban di poros gigi. Transmisi gigi baru skema direkomendasikan (lihat Gambar 2.b,c), di mana gear roda 4 dan roda gigi 1 dibuat integral. Rodagigi 1 sudah terpasang pada poros 2 dengan menggunakan lengan penyerap kejut 3 , dan roda gigi 4 dipasang pada poros 5 melalui ashock-absorber-sleeve 6 . Ketebalan peredam kejut-busing 3 dan 6 dipilih sesuai dengan rasio roda gigi diperhitungkan menggunakan persamaan 4 dan 5 .

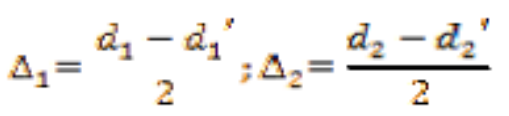

$$
U_{12}={ }_{\omega_{2}}^{\omega_{1}}=\frac{R_{2}}{R_{1}}=\frac{\Delta_{2}}{\Delta_{1}}
$$

Dimana d1, d1' - diameter guncangan luar dan dalam lengan penyerap 3gigi 1; d2, d2' - bagian luar danbagian dalam diameter semak penyerap kejut 6 roda 4; 1 Rdan 2 R - jari-jari lingkaran utama gigi 1 dan roda4; 1 ? dan 2 ? - kecepatan sudut gigi 1 dan roda 4; $12 \mathrm{U}$-rasio roda gigi.

Pemodelan MK7 Type Arresting Gear System

Struktur dasar dan prinsip kerja penangkapan tipe MK7 sistem roda gigi ditunjukkan pada Gambar 1. Selama pendaratan dek, tailhook pesawat menangkap dek independen (1) yang sebuah salib. Pendent terhubung melalui muffles2) dengan dua kabel pembelian (3) di kedua ujungnya. Setiap pembelian kabel dipasang kembali melalui fixed (5) dan moveable (8) pengangkutan satu grup, dan titik akhir terhubung oleh anchor damper (9). Gerbong yang dapat dipindahkan terpaksa berjalan menuju kereta tetap ketika tali ditarik oleh pesawat terbang. Dan oli hidrolik di silinder utama (6) mengalir keluar karena pendorong (7) dari silinder hidrolik diperbaiki dengan themovable carriage.

Aliran ini dipisahkan menjadi beberapa bagian. Yang utama melewati kontrol run out konstan katup (10) yang area terbukanya secara pasif disesuaikan selama proses pendaratan untuk menghasilkan gaya retraksi yang mantap untuk memperlambat pesawat. Yang 
kecil pergi ke jangkar dampers (9) untuk memberikan gaya redaman untuk menyerap guncangan dan getaran kabel pembelian. Lagi pula saat tailhook dari pesawat menangkap liontin geladak pada tahap awal, disana muncul getaran tali yang parah.

Dua sheave damper instalasi (4) diperkenalkan untuk mengurangi amplitudo getaran dalam dek independen. Jelas, sistem penangkapan peralatan rumit sistem ditambah mekanik dan hidrolik yang berisi benda tegar, tali fleksibel, dan unit hidrolik. Semuanya akan dimodelkan di sini melalui sistem multibody yang dinamis pendekatan seperti yang diilustrasikan pada Gambar 3.

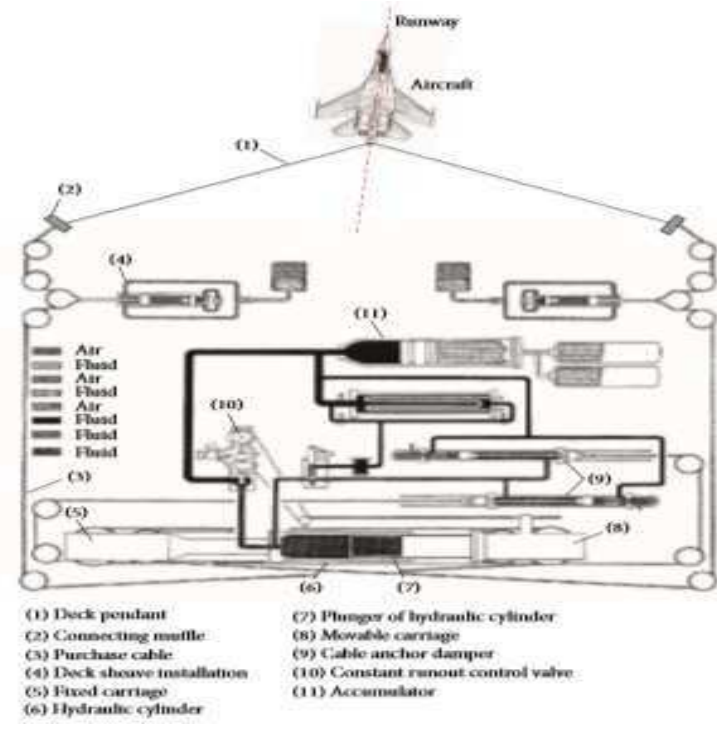

Gambar 3. Struktur dan prinsip kerja sistim roda gigi penangkap MK7

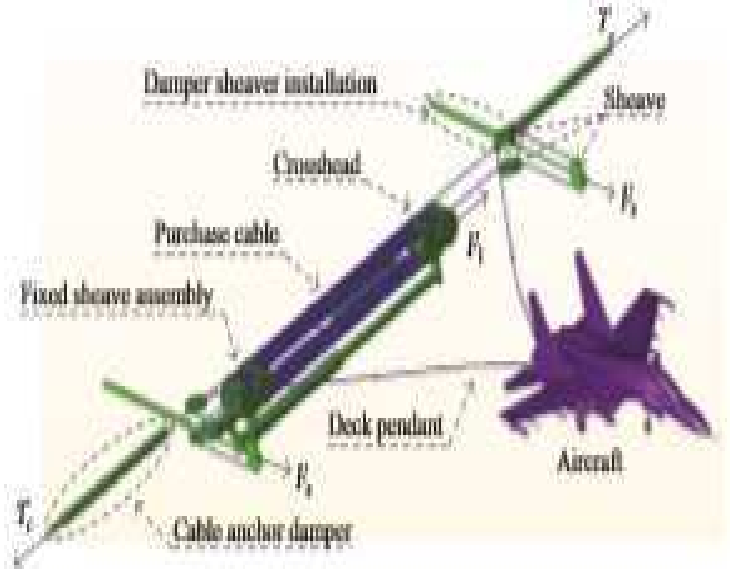

Gambar 4. Model multibodi sistim roda gigi penangkap

Ketika menurunkan ketergantungan sudut rotasi lengan penyerap kejut pada besarnya momen eksternal (momen mengemudi diporos), maka tabung berdinding tipis dipilih dengan ketebalan dinding dan jari-jari internal di lengan (gambar 5). Karena deformasi karet tabung ini, lengan luar dari tulangan shock absorber akan berputar dengan sudut kecil, dan untuk sudut geser karet tabung berdasarkan persamaannya 6 .

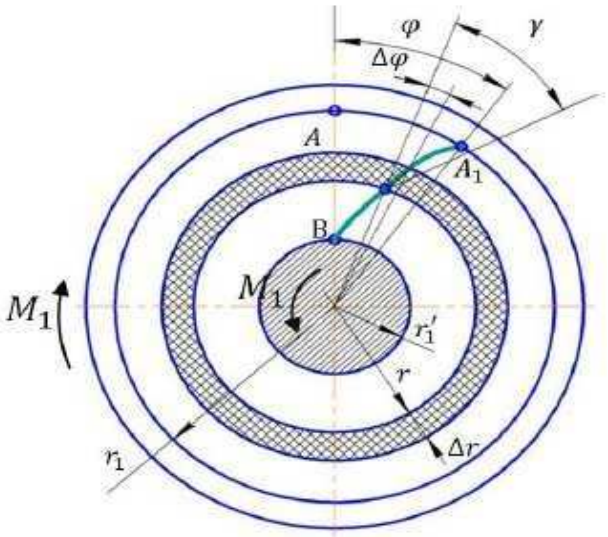

Gambar 5. Skema menghitung regangan geser roda gigi

$\operatorname{tg} V=\frac{\Delta \varphi_{1} r}{\Delta r}$

Luas permukaan tabung geser karet yang dipilih : 
Junaidi, Pemodelan dan Simulasi Sistem Roda Gigi ...

$F=2 \pi r l$

Dimana l adalah lengan gigi.

Gaya geser yang melingkar dan bekerja pada karet adalah:

$$
Q=G F \operatorname{tg} r=2 \pi r l G \frac{r \Delta \varphi_{1}}{\Delta r}
$$

Dimana G adalah modulus geserkaret $\mathrm{N} / \mathrm{m} 2$, besarnya torsi eksternal (dari poros bergrak dan dari roda sebagai momen perlawanan).

$$
M_{1}=Q r=2 \pi G l r^{3} \frac{\Delta \varphi_{1}}{\Delta r}
$$

Sehingga diperoleh:

$$
\Delta \varphi_{1}=\frac{\Delta r M_{1}}{2 \pi G l r^{3}}
$$

Integrasikan dalam redistribusi didapatkan:

$$
\varphi_{1}=\frac{M_{1}}{2 \pi G l} \int_{r_{1}}^{\tau_{1}} r^{3}={ }_{2 \pi G l}^{M_{1}}\left[\begin{array}{cc}
1 & 1 \\
2\left(r_{1}\right)^{2} & -c_{2\left(r_{1}\right)^{2}}^{2}
\end{array}\right]
$$

Dengan cara yang sama dapat ditentukan:

$$
\varphi_{2}=\underset{4 \pi G l}{M_{2}}\left[\begin{array}{c}
1 \\
r_{1}^{\prime}{ }^{2}
\end{array}-\begin{array}{c}
1 \\
r_{2}{ }^{2}
\end{array}\right]
$$

Dalam hal ini, rasio roda gigi dari roda gigi adalah variabel, yaitu ditentukan dari ekspresi berikut:

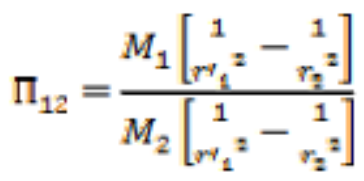

\section{HASIL DAN PEMBAHASAN}

Berdasarkan solusi numerik dari persamaan (10) dan ketergantungan grafis dari perubahan geser sudut deformasi bushing karet elastis dari roda gigi pada variasi nilainilai geser karet modulus dan torsi eksternal dapat diplot dan diperlihatkan pada gamnar 6. Sebuah analisis menunjukkan ketergantungan grafis yang diperoleh dengan peningkatan momen eksternal M1 danM2, peningkatan regangan dari pergeseran sudut karet busing pada gigi $\varphi 1$ dan $\varphi 2$ bersifat linier. Jadi, dengan peningkatan M1 dan M2, dari 0,062 x $10^{2} \mathrm{Nm}$ ke 0,37 $\mathrm{x} 10^{2} \mathrm{Nm}$ meningkat dari $0,094 \times 10^{-1}$ rad. Menjadi $0,24 \times 10^{-1}$ rad dengan sudut $\varphi 1$ meningkat menjadi $0,402 \times 10^{-1}$ rad. Oleh karena itu, untuk selongsong karet elastis dari gigi $\varphi 2$ naik menjadi $0,71 \mathrm{x}$ $10^{-1} \mathrm{rad}$.

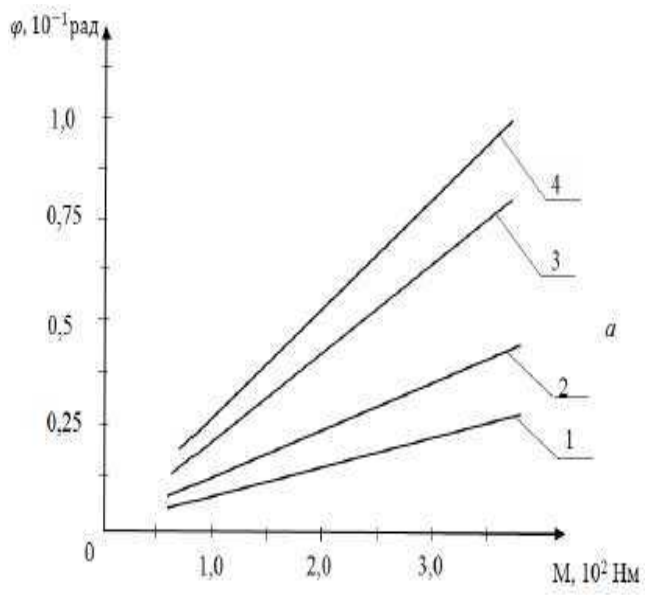

(a) 


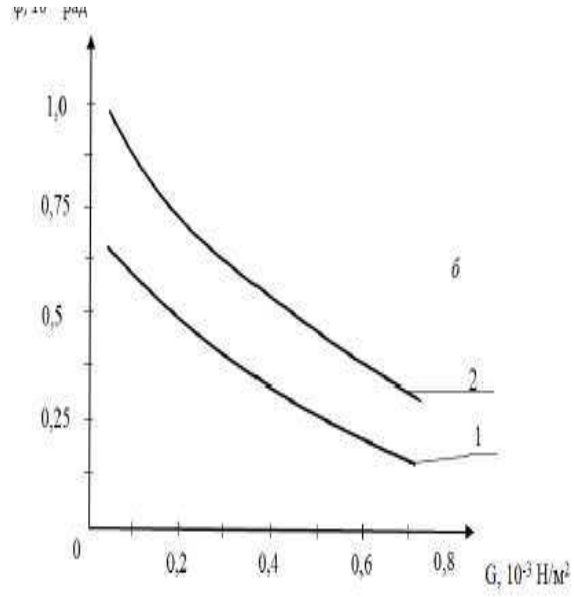

(b)

Gambar 6. Grafik ketergantungan dari perubahan strain terhadap pergeseran sudut peredam kejut - gear busing dan roda transmisi pada variasi torsi pada poros (a) dan modulus geser (b)

Untuk mengurangi interaksi dampak gigi selama pertunangan karena nilai besar $\varphi 1$ dan $\varphi 2$, nilai momen eksternal yang dapat diterima adalah $\mathrm{M} 1$ $=(0,025 \ldots 0,028) \times 10^{2} \mathrm{Hm}, \mathrm{M} 2=(0,03 \ldots$ $0,036) \times 10^{2} \mathrm{Nm}$. Untuk mengurangi nilai-nilai regangan pergeseran sudut bushing karet, modulus geser $\mathrm{M} 3=$ $(0,33 \ldots 0,42) \times 10^{-3} \mathrm{Nm}$.

\section{KESIMPULAN}

Sumber daya yang efektif adalah penghematan desain transmisi gigi dengan roda komposit dan elemen elastis telah dikembangkan. Rekomendasi metode menentukan tingkat sensitivitas roda gigi dengan elemen elastis. Mempelajari tegangan geser elemen elastis roda dan mendapatkan formula untuk menentukan rasio roda gigi.

Proses penangkapan adalah dinamika kopling yang rumit antara benda tegar, badan lentur, dan unit hidrolik. Ini non linier yang kuat dan melibatkan kedua perambatan gelombang sementara proses dalam tali dan perlambatan pesawat yang mulus.Fakta ini mengabaikan efisiensi penghitungan metode eksplisit karena proses sebelumnya memerlukan langkah waktu kecil untuk menangkapacara propagasi, sedangkan yang berikutnya membutuhkan langkah waktu yang besar untuk mempercepat.

Simulasi dinamis menunjukkan bahwa tegangan kabel mendominasi oleh propagasi, penolakan, dan superposisi dari gelombang stres selama tahap awal proses penangkapan, dan kemudian goncangan cepat hilang oleh sheave damperinstalasi dan peredam jangkar kabel. Hasil simulasi ulangi bahwa nilai stres maksimum terjadi ketika stres gelombang dipantulkan dan diletakan di antara tumpukan berkas gandum. Dan tekanan maksimum dalam kasus pendaratan off centerline adalah sedikit lebih kecil dari sepanjang kasus pendaratan centerline.

\section{REFERENCES}

[1] I. I. Artobolevsky, Theory of mechanisms and machines, Moscow: Nauka, 1988, .

[2] K. V. Frolov, Theory of mechanisms and machines, Moscow: Nauka, 1987.

[3] A. Djuraev and J. K. Beknazarov, "Development of designs and methods for calculating gears with variable parameters and elastic elements," International journal of advanced research in science, engineering and technology, vol. 5, no. 2, pp. 212 - 227, 2018.

[4] A. Dzhuraev and S. H. Kenzhaboev, "Development of constructive schemes and the scientific basis for the analysis and synthesis of link mechanisms with elastic elements and flexible links of the 
Junaidi, Pemodelan dan Simulasi Sistem Roda Gigi ...

drives of technological machines," Machines, vol. 14, no. 3, pp. 267-282, 2019.

[5] O. Sayfidinov and J. K. Beknazarov, "New prototype theory for gear transmission," Mechanical Engineering Journal, vol. 9, no. 2, pp. 78 - 93, 2018.

[6] Z. Chengbang, "Arester pesawat dengan kapal induk dan teknik kuncinya," Weapons Spectacle, vol. 6, no. 1, pp. 75-87, 2018.

[7] W. Haizhen, Kapal induk, Ordonansi Pengetahuan, Beijing, 2011.

[8] W. Billec, Pengaruh Deck Span Pada Performa Gear Penangkapan, Praha: DTIC Document AD813761, 1967.

[9] Z. Zhuokun, "Analisis dinamika untuk pesawat berbasis menguap dan penangkapan di luar pusat," Astronautik, vol. 11, no. 3, pp. 122 - 137, 2010. 